Original research article

\title{
Cross talk between redox signalling and metabolic activity of osteoblasts and fibroblasts in the presence of hydroxyapatite-based biomaterials influences bone regeneration
}

\author{
Ewa Ambrożewicz ${ }^{1}$, Grażyna Tokajuk ${ }^{2}$, Marta Muszyńska ${ }^{1}$, Ilona Zaręba ${ }^{3}$, Elżbieta Skrzydlewska ${ }^{1 *}$ \\ ${ }^{1}$ Medical University of Bialystok, Faculty of Pharmacy, Department of Analytical Chemistry, Bialystok, Poland \\ ${ }^{2}$ Medical University of Bialystok, Faculty of Medicine, Department of Integratet Dentistry, Bialystok, Poland \\ ${ }^{3}$ Medical University of Bialystok, Faculty of Pharmacy, Department of Medicinal Chemistry, Bialystok, Poland
}

\begin{abstract}
Regeneration of bone tissue defects that result from metabolic disorders, including periodontal diseases, can be supported by biomaterials based on hydroxyapatite. Despite of good biocompatibility of biomaterials they can cause oxidative stress and inflammatory processes as a result of mechanical interaction with surrounding tissues. Because osteoblasts are responsible for bone regeneration process in which gingival fibroblasts may also participate, the aim of the work was to investigate the influence of hydroxyapatite-based biomaterials (allogeneic and xenogeneic) and biomaterials combined with enamel matrix derivative (Emdogain) on osteoblast and fibroblast redox balance in the context of osteoblast proliferation and differentiation.

The results showed that examined substitutes were not cytotoxic in vitro, but affected redox balance of osteoblasts and fibroblasts (ROS level increase and GSH level decrease) which led to oxidative stress (MDA and protein carbonyl groups level increase) resulting in an increase of the Nrf2 and NFkB expression. The consequence of these changes was partial inhibition of proliferation and osteoblast differentiation. Emdogain alone and combined with biomaterials decreased ROS generation and increased GSH level in both osteoblasts and fibroblasts leading to reduction of transcription factors expression especially proinflammatory NFkB, which promoted osteoblast differentiation and mineralization process.
\end{abstract}

Keywords: Biomaterials; Bone regeneration; Fibroblasts; Osteoblasts; Oxidative stress

\section{Introduction}

Bone is a vascularized tissue with a unique capacity to repair itself (Mrakovcic et al., 2010). Bone regeneration and fracture repair involve the coordination of multiple events including migration, differentiation, and activation of osteogenic cells (Colnot et al., 2005). This is important for periodontology and maxillofacial surgery, particularly for patients who suffer from weakness, deformation, or even loss of bone tissue as a result of pathological processes (Baldini et al., 2011). In these situations, the optimal solution is to use bone-derived biomaterial such as hydroxyapatite, which is the primary inorganic component of bone tissue. Moreover, hydroxyapatite exhibits excellent biocompatibility in relation to bone cells as well as gingival fibroblasts (Inayat-Hussain et al., 2004; Tseng et al., 2013). Upon insertion into the bone defect, hydroxyapatite serves as a scaffold for osteogenic cells (osteoconductive activity) and supports regenerative processes (Kolk et al., 2012).
Numerous studies have shown that hydroxyapatite from animal bones may affect the proliferation and differentiation of osteoblasts and fibroblasts to varying degrees, depending on chemical composition, granulation, and porosity of the hydroxyapatite (Baldini et al., 2011; Kübler et al., 2004). Bone regeneration may also be hindered due interactions between the bone-derived biomaterials and surrounding hard and soft tissues. Biomaterial implantation may lead to inflammation and as a result, prolong wound healing (Morais et al., 2010). This has been associated with increased generation of reactive oxygen species (ROS), leading to redox imbalance, which in turn, is an important pro-inflammatory factor leading to both local and systemic pathologies (Biswas, 2016). ROS may also result in oxidative modification of proteins, lipids, and DNA of osteoblasts or other soft tissue cells surrounding the bone, such as gingival fibroblasts (Xu et al., 2012).

To reduce the side effects of hydroxyapatite on cellular metabolism, combinations with growth factors, platelet-rich plasma, or bone marrow cells have been previously investi-

\footnotetext{
* Author for correspondence: Elżbieta Skrzydlewska, Medical University of Białystok, Faculty of Pharmacy, Department of Analytical Chemistry, Mickiewicza 2d, 15-222 Białystok, Poland; e-mail: elzbieta.skrzydlewska@umb.edu.pl http://doi.org/10.32725/jab.2019.004
}

Submitted: 2018-06-06 • Accepted: 2019-01-16 • Prepublished online: 2019-03-19

J Appl Biomed 17/2: 125-135 • EISSN 1214-0287 • ISSN 1214-021X

(c) 2019 The Authors. Published by University of South Bohemia in České Budějovice, Faculty of Health and Social Sciences.

This is an open access article under the CC BY-NC-ND license. 
gated (Behnia et al., 2013; Ozeki et al., 2008). Hydroxyapatite surfaces are often modified with various substances, such as metal ions, e.g. $\mathrm{Li}^{+}, \mathrm{Eu}^{3+}$ (Marycz et al., 2017). Consequently, modified biomaterials acquire new properties, such as antimicrobial (Marycz et al., 2016) or antioxidant (Kornicka et al., 2017). Moreover, hydroxyapatite was combined with enamel matrix derivative, Emdogain, extracted from porcine fetal teeth (Miron, 2017). Biologically active ingredients of this biomaterial, including the amelogenin proteins, play a key role in the development of teeth and other supporting structures (Jiang et al., 2006). Emdogain was originally developed to regenerate periodontal tissues, such as epithelial cells, gingival and periodontal fibroblasts, and ligament cells (Sculean et al., 2011). However, it has also been shown to affect osteoblast metabolism by enhancing viability and proliferation, supporting cellular adhesion, and increasing cell mobility and differentiation (Wada et al., 2012).

The aim of this study was to compare the effects of hydroxyapatite or hydroxyapatite in combination with Emdogain on the metabolic activity of osteoblasts and fibroblasts. Factors involved in maintaining the redox balance of cells were assessed, as well as the effects of oxidative stress on osteoblast mineralization. A number of different hydroxyapatites of various origin (allogeneic: Maxgraft; xenogeneic: Cerabone, Apatos, and Genos) and composition (hydroxyapatite: Maxgraft, Cerabone, Apatos; collagen-enriched hydroxyapatite: Genos) were used in this study.

\section{Materials and methods}

\section{Materials}

To evaluate the in vitro effect of biomaterials on osteoblasts metabolism various commercial materials of different origin and chemical composition have been studied. Four different hydroxyapatites: human origin (Maxgraft, particale size $<2.0 \mathrm{~mm}$, Botiss Biomaterials $\mathrm{GmbH}$, Germany), bovine origin (Cerabone, particale size 1.0-2.0 mm Botiss Biomaterials $\mathrm{GmbH}$, Germany), porcine origin (Apatos, particale size 0.6$1.0 \mathrm{~mm}$ Tecnoss, Italy), porcine hydroxyapatite with preserved collagen (Genos, particale size $0.25-1.0 \mathrm{~mm}$, Tecnoss, Italy) as well porcine enamel matrix derivative (Emdogain, Straumann, Switzerland) were used for experiments.

\section{Cell culture and treatment}

All experiments were carried out using normal human foetal osteoblast cell line (hFOB 1.19) and human fibroblasts (CCD 1112Sk) obtained from ATCC (American Type Culture Collection, Menassas, VA). Osteoblasts were cultured in 1:1 DMEM/F-12, with $0.3 \mathrm{mg} / \mathrm{ml} \mathrm{G418,} 100 \mathrm{U} / \mathrm{ml}$ penicillin, $100 \mu \mathrm{g} / \mathrm{ml}$ streptomycin and $10 \%$ FBS and incubated at $34{ }^{\circ} \mathrm{C}$ in a $5 \% \mathrm{CO}_{2}$ and $95 \%$ in air atmosphere. To induce the osteoblast differentiation process, cells were cultured in mineralization medium supplemented with $0.05 \mathrm{mg} / \mathrm{ml}$ ascorbic acid, $10 \mathrm{~mm}$ sodium $\beta$-glycerophosphate and $10^{-7} \mathrm{M}$ dexamethasone and maintained at $39^{\circ} \mathrm{C}$ (Czekanska et al., 2012). Fibroblasts were cultured in a humidified atmosphere of $5 \% \mathrm{CO}_{2}$ at $37{ }^{\circ} \mathrm{C}$ DMEM containing FBS (10\%) and supplemented with $50 \mathrm{U} / \mathrm{ml}$ penicillin and $50 \mu \mathrm{g} / \mathrm{ml}$ streptomycin.

To examine effect of biomaterials on cells viability, ROS, GSH level, lipid and protein modifications as well as transcription factors Nrf2 and NFkB expression in osteoblasts and fibroblasts, cells were carried out on 6 -well plates. For those experiments $1 \times 10^{5}$ cells/well were seeded. When the cells reached confluence, $100 \mathrm{mg} /$ well of hydroxyapatites (Max- graft, Cerabone, Apatos, Genos) and $100 \mu \mathrm{g} / \mathrm{ml}$ of Emdogain were added to appropriate wells. The level of examined parameters was determined after 24 and/or 48 hours. To proliferation and differentiation assays, osteoblasts were seeded on the hydroxyapatites ( $30 \mathrm{mg} /$ well) at density $5 \times 10^{4}$ cells/well and cultured on 24-well plates. Emdogain was added in concentration $100 \mu \mathrm{g} / \mathrm{ml}$ in mineralization medium to cells during each medium exchange to appropriate wells. Control cells were incubated in parallel without hydroxyapatites. Cells were collected after 4, 7, 14 and 21 days.

\section{Cell viability assay}

Cellular membrane integrity was monitored using the assay based on the determination of the release of lactate dehydrogenase (LDH) into the medium after 24 and 48 hours. The activity of LDH in medium, as well as in cell lysates was measured spectrophotometrically with detection at $340 \mathrm{~nm}$ as described by Fotakis and Timbrell (2006).

\section{Redox homeostasis estimation}

Determination of ROS level

The generation of total ROS level was detected using an electron spin resonance (ESR) spectrometer e-scan (Noxygen $\mathrm{GmbH}$ /Bruker Biospin $\mathrm{GmbH}$, Germany), where selective interaction of the spin probes $\mathrm{CMH}$ (1-hydroxy-3-methoxy-carbonyl-2,2,5,5-tetrame-thylpyrrolidine) with ROS forms a stable nitroxide CM-radical. The kinetics of this radical accumulation was measured according to the electron spin resonance (ESR) amplitude of the low field component of ESR spectra (Kuzkaya et al., 2003).

\section{Determination of GSH level}

Glutathione (GSH) level was quantified in cells lysates (osteoblasts and fibroblasts) using capillary electrophoresis (CE) method with UV detection at $200 \mathrm{~nm}$ as described by Maeso et al. (2005).

\section{Estimation of Nrf2 and NFKB expression}

Western blot analysis of Nfr2 and NFkB was performed according to Eissa and Seada (1998). Briefly, lysates were mixed with sample Laemmli buffer containing 5\% 2-mercaptoethanol, heated at $100^{\circ} \mathrm{C}$ for $7 \mathrm{~min}$, and separated by $10 \%$ Tris-Glycine SDS-PAGE. Primary monoclonal antibodies were raised against Nfr2, NFkB (Santa Cruse Biotechnology, USA) and $\beta$-actin (Sigma-Aldrich, St. Louis, USA). Protein bands were visualized using the BCIP/NBT Liquid substrate system (Sigma-Aldrich, St. Louis, USA) and quantitated using the Versa Doc System and Quantity One software (Bio-Rad Laboratories Inc., CA).

\section{Determination of lipid and protein modifications}

MDA was measured by GC/MSMS in selected ion monitoring (SIM) mode, as the O-PFB-oxime or O-PFB-oxime-TMS derivatives by the methods described previously (Gęgotek et al., 2017). Carbonyl groups were determined spectrophotometrically using 2,4-dinitrophenylhydrazine (Augustyniak et al., 2015). The absorbance was measured in the samples at $360 \mathrm{~nm}$ for carbonyl content and at $280 \mathrm{~nm}$ for protein concentration estimation. Carbonyl content was calculated, using the molar absorption coefficient of $22.000 \mathrm{M}^{-1} \mathrm{~cm}^{-1}$.

\section{Proliferation assay - Determination of DNA biosynthesis}

Osteoblasts proliferation rate was assessed in mineralization conditions by measurement of DNA biosynthesis using labe- 
led thymidine. $0.5 \mu \mathrm{Ci} / \mathrm{ml}$ of [methyl ${ }^{3} \mathrm{H}$ ] thymidine (Hartman Analytic $\mathrm{GmbH}$, Braunschweig, Germany) was added to osteoblasts incubated for $24 \mathrm{~h}$ in the wells. After medium removing, cells were rinsed with $\mathrm{PBS}$ and solubilized with $0.1 \mathrm{~mol} / \mathrm{l}$ sodium hydroxide containing 1\% SDS and the amount of built-labeled thymidine was measured in the cell lysate. Incorporation of the tracer into DNA was measured using scintillation counter - LiquidScintillation Analyzer Tri-Carb 2810 TR (Perkin Elmer) and software QuantoSmart TM (Perkin Elmer) after $4,7,14,21$ days of culture in mineralization condition. DNA biosynthesis is shown as a percentage of radiation of cells with bone substitutes with respect to the negative control cells.

\section{Differentiation assays}

Determination of alkaline phosphatase activity

Alkaline phosphatase activity (ALP) was determined by fluorometric assay kit (StemTAG Alkaline Phosphatatase Activity Assay Kit, Cell Biolabs, INC.) at Ex/Em 480/520 nm. The tests were performed according to the manufacturer protocol. The activity of ALP was expressed as amount of enzyme that catalyses the reaction with substrate per minute per mg of protein.

\section{Determination of collagen synthesis}

Biosynthesis of type I collagen was evaluated according to the method of Peterkofsky et al. (1982). $5 \mu \mathrm{Ci} / \mathrm{ml}$ of L[U-'4C] proline (Hartman Analytic $\mathrm{GmbH}$, Braunschweig, Germany) was added to cells culture and the mixture was incubated for $24 \mathrm{~h}$. Incorporation of the tracer into collagen was determined, after digesting proteins with purified Clostridium histolyticum collagenase (Sigma-Aldrich, Saint Louis, Missouri, USA), in scintillation counter (Perkin Elmer, Waltham, USA). Collagen biosynthesis is shown as a percentage of radiation of cells with bone substitutes with respect to the negative control cells.

\section{Immunofluorescence staining for type I collagen}

Cells were fixed with $3.7 \%$ paraformaldehyde and permeabilized with $0.01 \%$ TritonX100. After blocking with 3\% FBS, cells were incubated with antibody anti-collagen type I [Sigma, 1:1000]. Next, cells were washed with PBS and incubated with FITC goat anti-rabbit IgG (554001, B\&D, 1:1000). To visualize cell nucleus, cells were incubated with Hoechst 33342. Samples were visualized with confocal laser scanning microscope BD Pathway 855 Bioimager (B\&D) using AttoVision software (B\&D).

\section{Determination of osteocalcin level}

The osteocalcin concentration was determined spectrophotometrically at $450 \mathrm{~nm}$ in culture supernatant using commercially available human-specific ELISA kit (Quantikine ELISA, Human Osteocalcin Immunoassay, R\&D systems). The tests were performed according to the manufacturer protocol.

\section{Statistical analysis}

Data were analysed by using standard statistical analyses, one-way/two-way analysis of variance (ANOVA) to determine significant differences between different groups. The results are expressed as the mean \pm standard deviation (SD) for $n=5$. $P$-values less than 0.05 were considered as significant.

\section{Results}

\section{Biochemical studies}

Bone-derived hydroxyapatites added to culture medium of osteoblasts and fibroblasts led to changes in cells viability. The results show that none of the biomaterials was toxic to osteoblasts (Fig. 1). In contrast, Cerabone and Apatos were the most toxic to fibroblasts resulting a 29\% (Cerabone) and 22\% (Apatos) reduction in cells viability after $24 \mathrm{~h}$, and a 27\% (Cerabone) and 25\% (Apatos) reduction after $48 \mathrm{~h}$ (Fig. 1B). However, addition of Emdogain to cultures of both cell lines resulted in approximately $20 \%$ increase in cells viability compared to controls. Emdogain also significantly increased the viability of osteoblasts and fibroblasts cultured in the presence of hydroxyapatites. Because the viability of cells after 24 and 48 hours was similar, all further measurements were performed after $24 \mathrm{~h}$.

Biomaterials were tested for disturbances of redox balance by monitoring ROS level. Bone-derived hydroxyapatites increased the level of ROS by $15-25 \%$ in osteoblasts and 30-65\% in fibroblasts (Fig. 2). Both cell lines had reduced ROS level when cultured with Emdogain, approximately 30\% reduction in comparison to controls. The protective effect of Emdogain was also observed when osteoblasts were incubated with hydroxyapatites. A reduction in ROS level of approximately 20-25\% compared to hydroxyapatite alone was observed. In the case of fibroblasts, the largest effect due to Emdogain was observed with Maxgraft (ROS level were reduced by approximately 45\%).
A

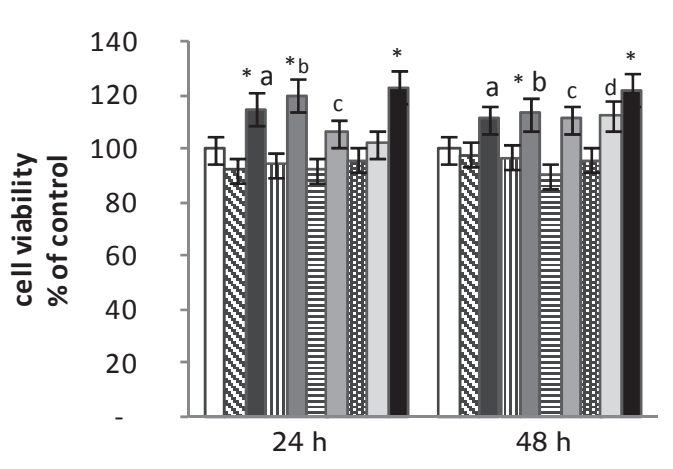

B

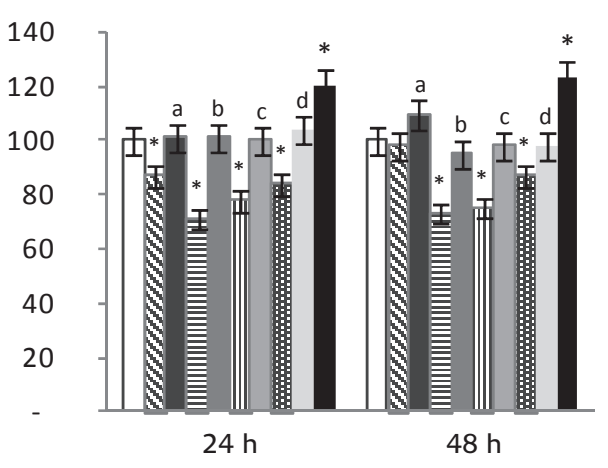

$\square$ Control $\triangle$ Maxgraft -Maxgraft+Emdogain ECerabone Cerabone+Emdogain m Apatos $\square$ Apatos+Emdogain Genos Genos+Emdogain - Emdogain

Fig. 1. The evaluation of biomaterials cytotoxicity on osteoblasts (A) and fibroblasts (B), by LDH test. * statistically significant differences vs. control; $p<0.05$;

$\mathrm{a} b \mathrm{~cd}$ statistically significant differences vs. Maxgraft, Cerabone, Apatos and Genos group, respectively. 

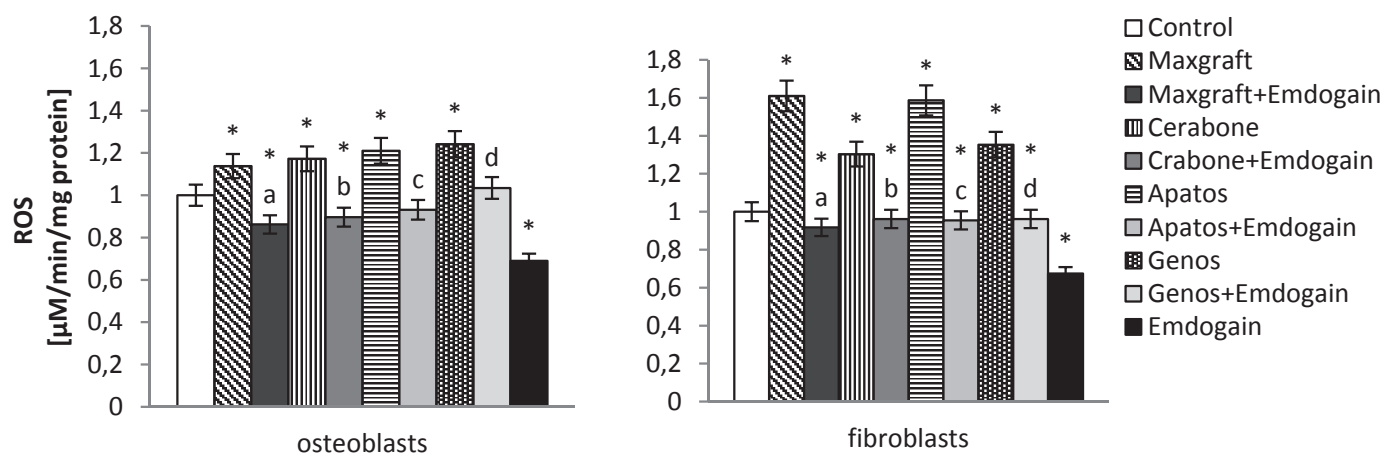

Fig. 2. ROS level generation in osteoblast and fibroblast cells after incubation with biomaterials for $24 \mathrm{~h}$.

* statistically significant differences vs. control; $p<0.05$

$\mathrm{a} b \mathrm{~cd}$ statistically significant differences vs. Maxgraft, Cerabone, Apatos and Genos group, respectively.

As a result of osteoblasts exposure to bone-related hydroxyapatites, a reduction in GSH levels was observed. In osteoblasts, decreases of $26 \%$ (Apatos) and 19\% (Maxgraft) and approximately $16 \%$ (Cerabone and Genos) were observed (Fig. $3)$. Fibroblasts were shown to be more resistant to the presence of hydroxyapatite, and significant differences were only observed with Apatos and Genos. Emdogain enhanced GSH level in both cell lines by approximately $17 \%$ for osteoblasts and $18 \%$ for fibroblasts, respectively. In osteoblasts cultured with Apatos and Maxgraft, Emdogain restored GSH level by $38 \%$ (Apatos) and 15\% (Maxgraft), whereas no significant effect of Emdogain on GSH was seen in fibroblasts cultured with bone-derived hydroxyapatites.
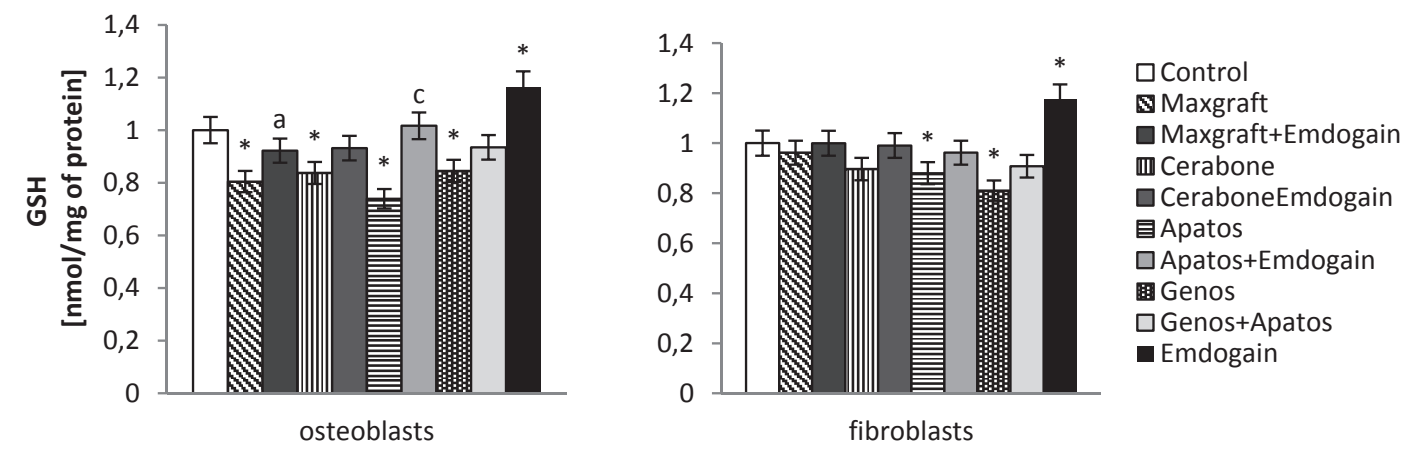

Fig. 3. GSH level in osteoblasts and fibroblasts cells after incubation with biomaterials for $24 \mathrm{~h}$.

* statistically significant differences vs. control; $p<0.05$;

a c statistically significant differences vs. Maxgraft, Cerabone, Apatos and Genos group, respectively.

Osteoblasts and fibroblasts responded to treatment with hydroxyapatites by enhancing the expression of transcription factor Nfr2. The largest increases were observed in osteoblasts incubated with Cerabone, Genos and Apatos (5-fold). Whereas only a 2.5-fold increase was observed in fibroblasts cultured with with Cerabone, Genos and Maxgraft (Fig. 4). The combination of hydroxyapatites with Emdogain resulted in a decrease in Nrf2 expression, particularly evident in osteoblasts cultured with Cerabone and Genos (2.5-fold) and fibroblasts cultured with Genos (2-fold).

Hydroxyapatites also affected NFkB expression. Expression of NFKB in osteoblasts increased with exposure to Cerabone (2-fold), Genos (2.5-fold), and Apatos (3-fold), and also in fibroblasts after exposure to Genos (6-fold), Cerabone (4-fold), and Apatos (3-fold) (Fig. 4). Levels of NFKB transcription factor were significantly decreased in both osteoblasts and fibroblasts cultured in the presence of hydroxyapatites combined with Emdogain. The largest effects were observed with Cerabone and Genos for both cell types.

Oxidative conditions after exposure of cells to bone-derived biomaterials resulted in oxidative modifications of lipids and proteins. Hydroxyapatites led to an increase in lipid peroxidation product (MDA) level in both cell lines. The greatest increase in MDA level of osteoblasts (195\% increase) and fibroblasts (40\% increase) was found for cells cultured with Genos, and fibroblasts cultured with Apatos (40\% increase) (Fig. 5). Adding Emdogain to cultures decreased MDA level by approximately $30 \%$ in both cell lines. In the case of osteoblasts incubated with hydroxyapatites, Emdogain with Cerabone had the strongest effect on cultured cells (50\% decrease compared to Cerabone alone). The strongest effect on cultured fibroblasts was observed with Maxgraft, Cerabone and Genos (approximately $35 \%$ decrease in all cases). 


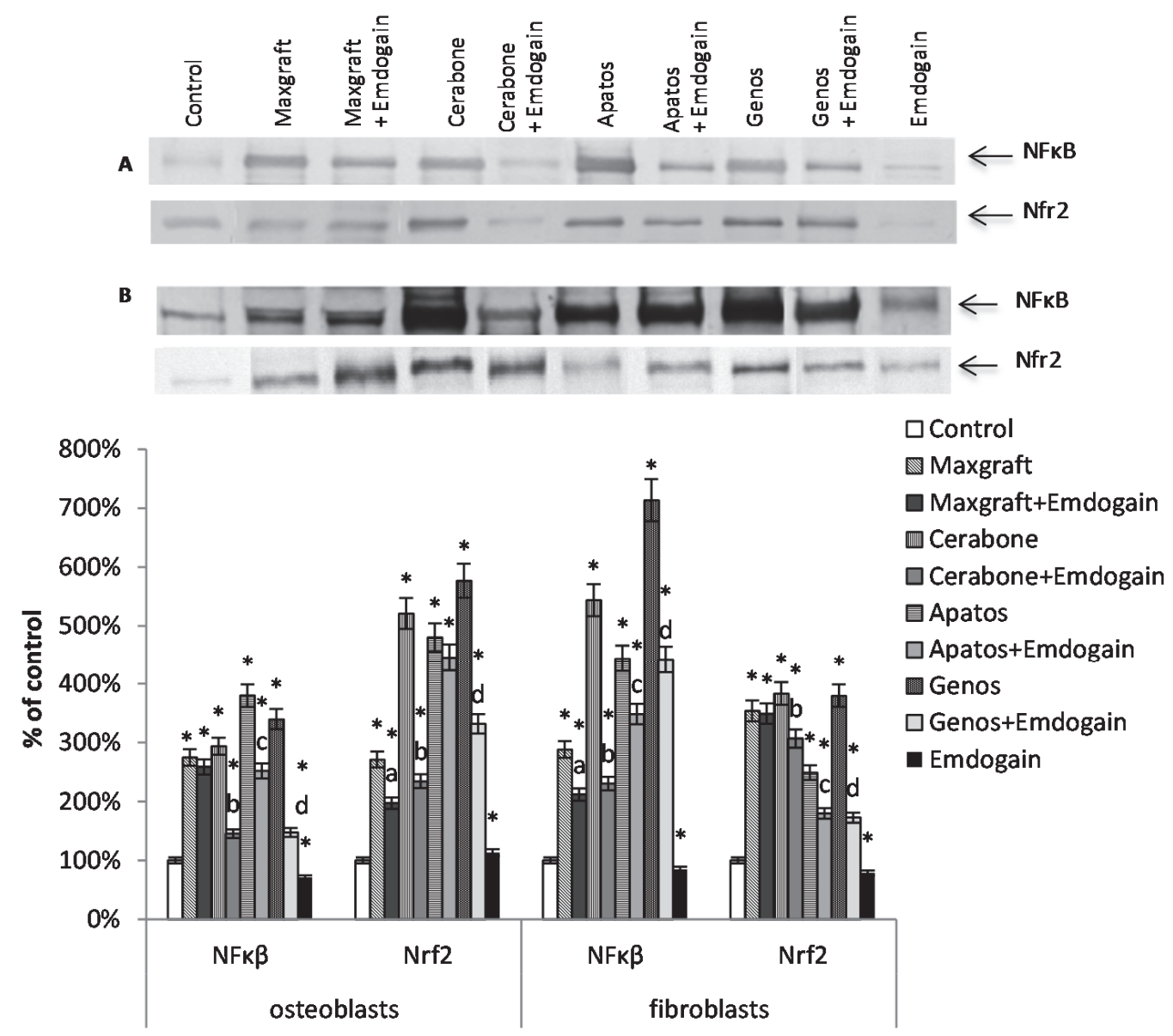

Fig. 4. Expression of $\mathrm{Nfr} 2$ and $\mathrm{NF \kappa B}$ in osteoblasts $(\mathbf{A})$ and fibroblasts $(\mathbf{B})$ cells after $24 \mathrm{~h}$ incubation with biomaterials. * statistically significant differences vs. control; $p<0.05$

a bcd statistically significant differences vs. Maxgraft, Cerabone, Apatos and Genos group, respectively.
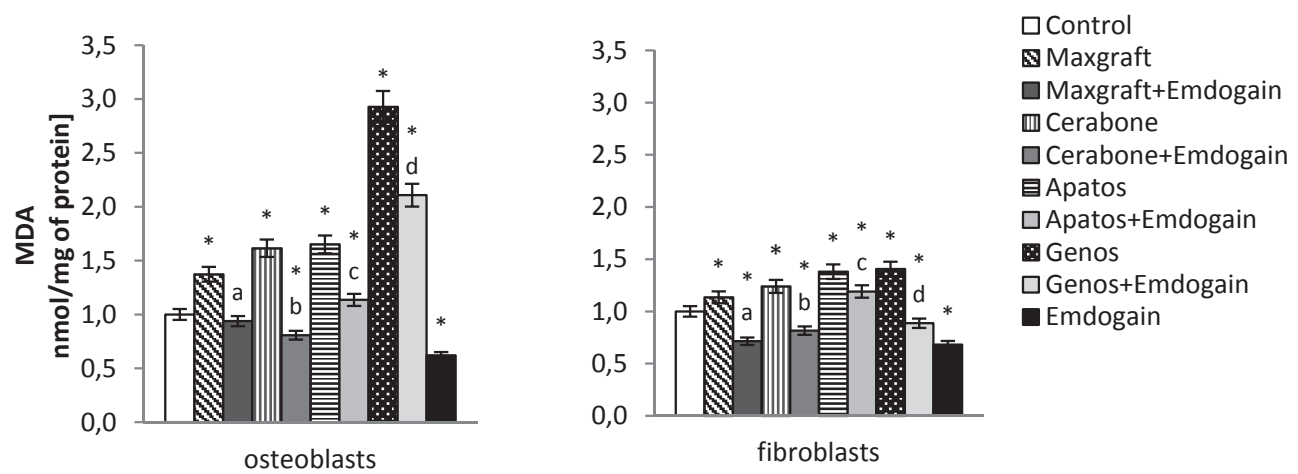

Fig. 5. MDA level in osteoblasts and fibroblasts cells after incubation with biomaterials for $24 \mathrm{~h}$.

${ }^{*}$ statistically significant differences vs. control; $p<0.05$

$\mathrm{abcd}$ statistically significant differences vs. Maxgraft, Cerabone, Apatos and Genos group, respectively.

In both the osteoblast and fibroblast cell lines, an increase in protein oxidative modification (carbonyl group) after exposure to bone-derived hydroxyapatites was observed. In the case of osteoblasts, biomaterials (Cerabone, Apatos, and Genos) caused an increase of approximately $30 \%$, whereas in fibroblasts, the greatest effect was observed with Genos $(101 \%$ increase). Emdogain did not significantly reduce level of carbonyl groups in osteoblast controls and osteoblasts cultured with hydroxyapatites, except Genos (15\% decrease compared to Genos without Emdogain) (Fig. 6). However, Emdogain alone significantly reduced carbonyl groups (by 21\%) in fibroblasts and protected proteins from oxidative damage caused by hydroxyapatites. In fibroblasts, Emdogain combined with Genos decreased carbonyl group level by $58 \%$ and by $50 \%$ with Apatos.

\section{Osteoblasts proliferation and differentiation}

Changes in proliferation and differentiation of osteoblasts were observed with the tested biomaterials. To evaluate cell division during the mineralization process in the presence of 

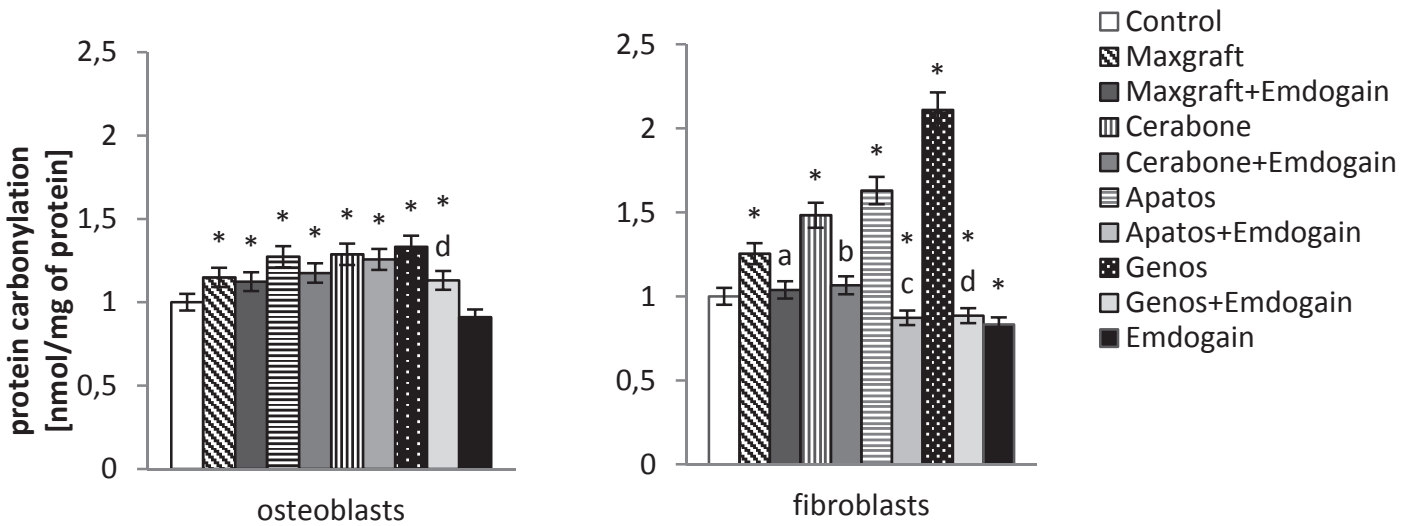

fibroblasts

Fig. 6. Carbonyl group level in osteoblasts and fibroblasts cells after $24 \mathrm{~h}$ incubation with biomaterials. $*$ statistically significant differences vs. control; $p<0.05$;

$\mathrm{abcd}$, statistically significant differences vs. Maxgraft, Cerabone, Apatos and Genos group, respectively.

different bone-derived hydroxyapatites, the rate of osteoblast proliferation was estimated according to DNA biosynthesis (Fig. 7). It was shown that DNA biosynthesis significantly increased up to day 7 and then gradually decreased until day 21. Differentiation of osteoblasts cultured with different hydroxyapatites was evaluated by collagen type I level, ALP activity, and osteocalcin level. Collagen deposits in cell cultures were also visually examined (Fig. 8). Collagen biosynthesis (Fig. 8) and ALP activity (Fig 7) were shown to progressively increase significantly after day 7. The highest levels were observed on day 14 of culture and finally decreased after 21 days. However, osteocalcin level in the medium of control cells also significantly increased from day 4 to 21 (Fig. 7).
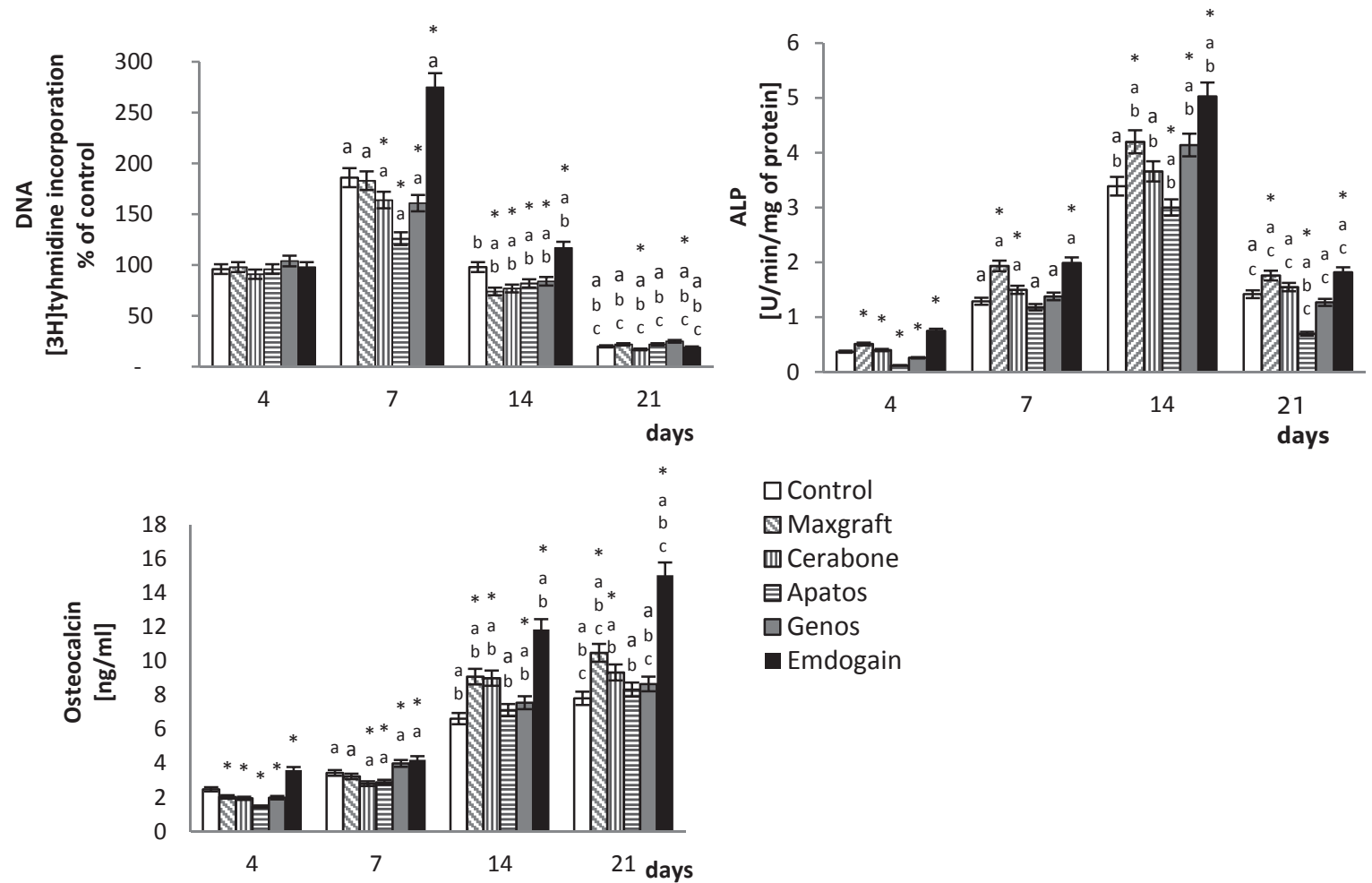

Fig. 7. The effect of biomaterials on the biosynthesis of DNA, ALP activity and osteocalcin level in osteoblasts.

* statistically significant differences vs. control; $p<0.05$

a b c statistically significant differences vs. 4 day, 7 day, 14 day, respectively. 


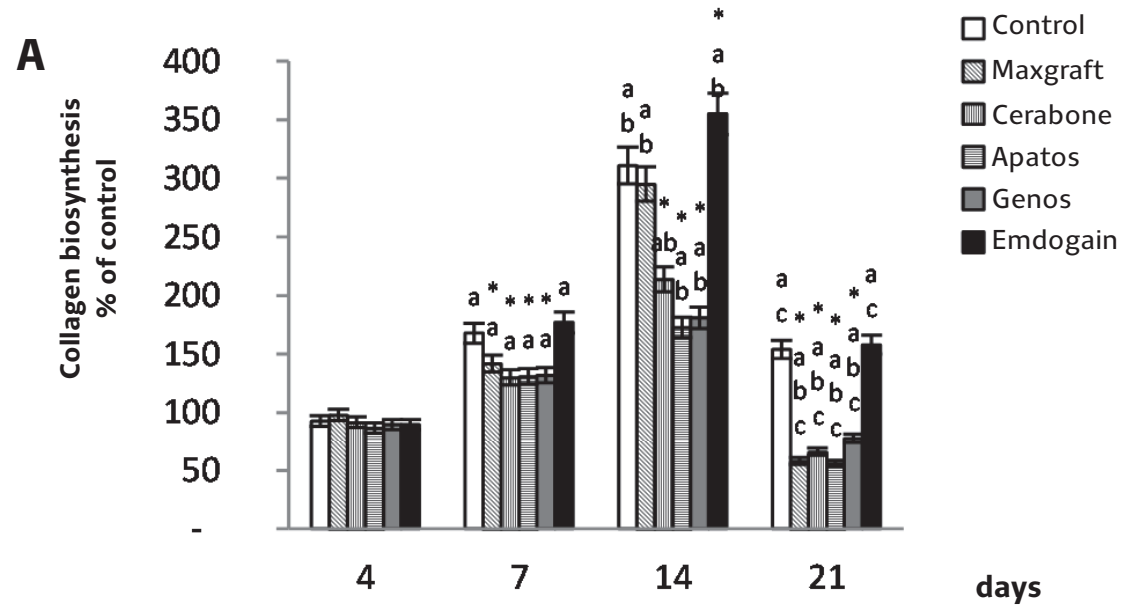

B
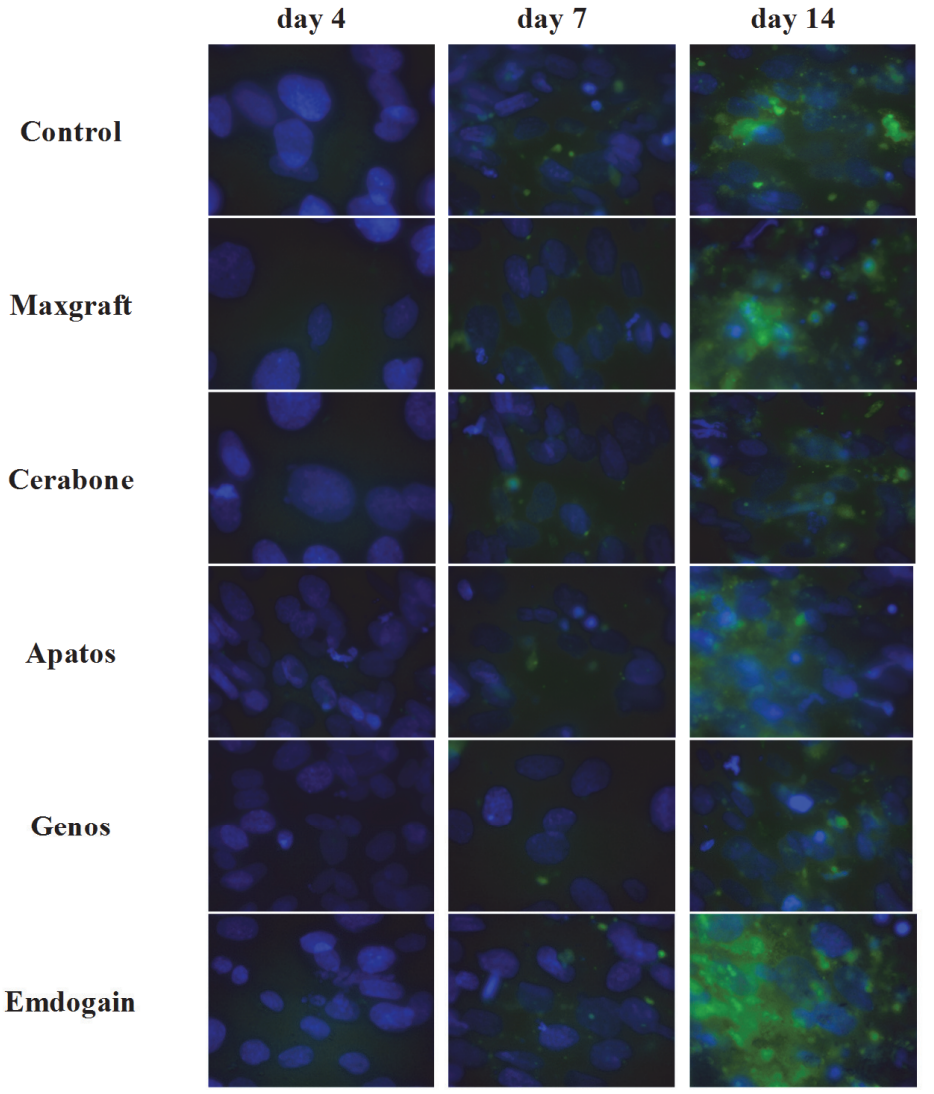

day 14

Fig. 8. The effect of biomaterials on the biosynthesis of type I collagen $(\mathbf{A})$ and visualization of type I collagen deposition $(\mathbf{B})$ in osteoblasts. Blue fluorescence is the DAPI staining of nuclei, whereas collagen provides green fluorescence.

* statistically significant differences vs. control; $p<0.05$

a b c statistically significant differences vs. 4 day, 7 day, 14 day, respectively.

Emdogain has a positive effect on the proliferation and differentiation of osteoblasts. Results show that addition of Emdogain to cultures caused less reduction in DNA biosynthesis after 7 and 14 days for all hydroxyapatites examined in this study (Fig. 9). Significant changes in collagen biosynthesis were also observed. Emdogain enhanced collagen level on day 7 by about 22\% (Maxgraft), 33\% (Cerabone), 30\% (Apatos), $25 \%$ (Genos) and on day 14 by approximately 14\% (Maxgraft), 20\% (Cerabone), 32\% (Apatos), 32\% (Genos). Moreover, Emdogain had no significant effect on ALP activity except Apatos. 

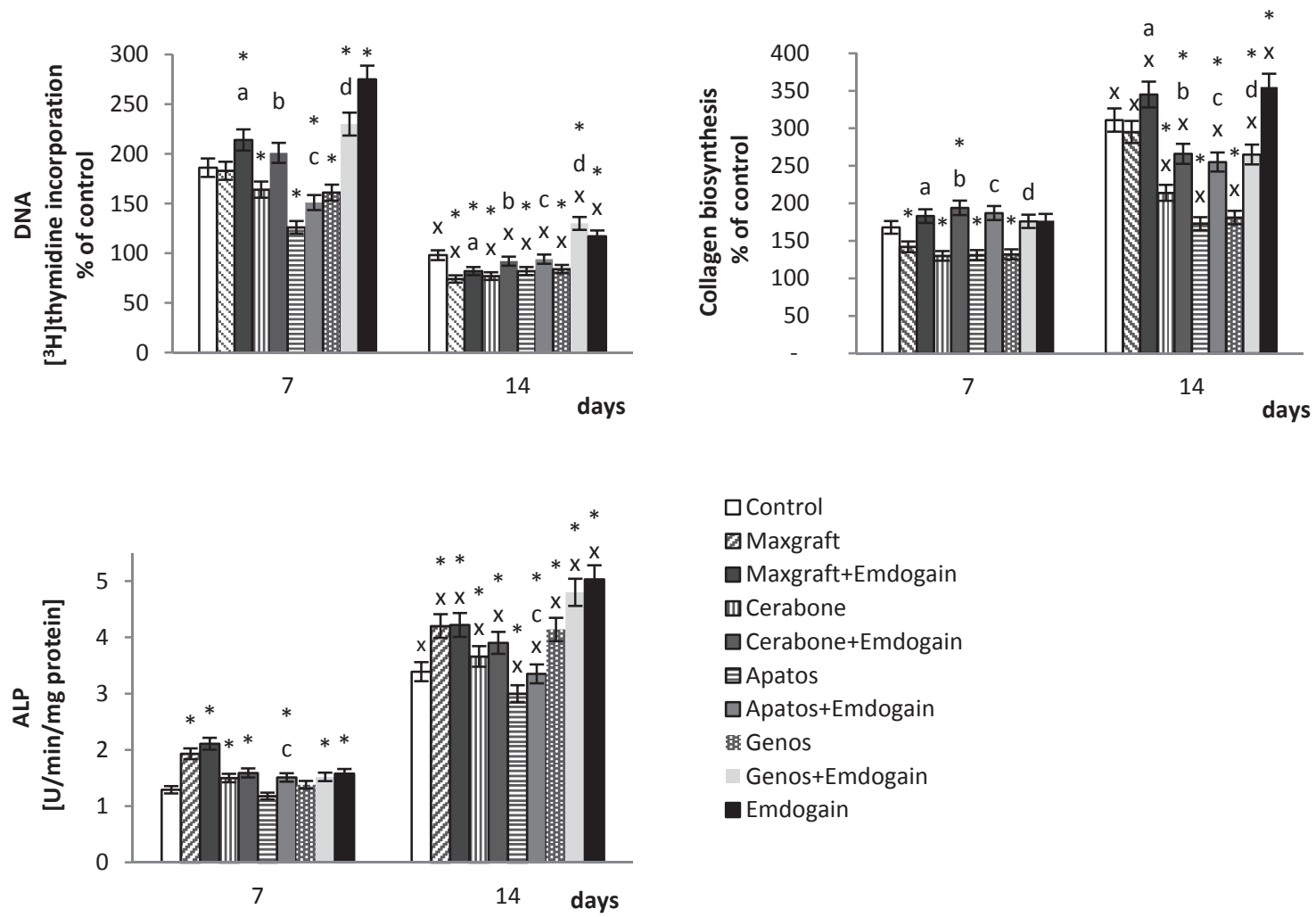

Fig. 9. The effect of Emdogain on the DNA biosynthesis, collagen biosynthesis and ALP activity in osteoblasts cultured with hydroxyapatites. Data points represent mean \pm SD $(n=5)$

* statistically significant differences vs. control; $p<0.05$

a bcd statistically significant differences vs. Maxgraft, Cerabone, Apatos and Genos group, respectively.

$\times$ statistically significant differences vs. 7 day.

\section{Discussion}

\section{Effect of hydroxyapatite-based biomaterials on proliferation and differentiation of osteoblasts}

Bone tissue regeneration in prosthetic and implantological treatment can be supported by the use of bone-based hydroxyapatites. However, biomaterials used in surgical procedures may influence the metabolic processes of bone and soft tissue surrounding bones (Anderson et al., 2008). Bone regeneration processes involve proliferation and differentiation of osteoblasts and other soft tissue cells. Osteoblasts are responsible for osteogenesis and mineralization, which later is manifested mainly as synthesis of type I collagen, ALP activity, and synthesis of osteocalcin, an extracellular calcium binding protein (Patti et al., 2013). However, wound healing is associated with normal migration and proliferation of soft tissue cells, particularly gingival fibroblasts (Rincon et al., 2003). A number of previous studies confirm that osteoblasts, as well as fibroblasts, may grow on hydroxyapatite, however, biosynthesis of DNA gradually decreases over subsequent weeks (Tagaya et al., 2011; Theiszova et al., 2008). Our results suggest hydroxyapatite may affect the mineralization process since production of collagen by osteoblasts grown on hydroxyapatites is lower than in controls, particularly in the case of biomaterials of xenogeneic origin, which may be caused by lowering the level of collagen type I gene expression (Huggins and Mendelson, 2017). As a consequence, an increase in collagen biosynthesis is followed by an increase in alkaline phosphatase activity therefore, hydroxyapatite enriched with collagen (Genos) results in a more intensive increase in alkaline phosphatase activity compared to hydroxyapatite of the same origin without collagen (Apatos). Enhanced ALP activity in the presence of hydroxyapatite has been confirmed by other authors (Kübler et al., 2004). Hydroxyapatite was also found to enhance osteoblast activity related to the transport of calcium to cells, estimated by osteocalcin level (Patti et al., 2013). The results of this study show that osteocalcin level is most effectively elevated by allogeneic hydroxyapatites (Maxgraft), whereas xenogeneic porcine hydroxyapatite (Apatos) decreases osteocalcin level.

\section{Effect of hydroxyapatite-based biomaterials on redox conditions in osteoblasts and fibroblasts}

In general, bone-based hydroxyapatites are perceived as safe for medical and dental applications due their relatively high biocompatibility. From a mechanical or chemical perspective they may contribute to damage of osteoblasts and fibroblasts, impairing metabolic function of these cells (Anderson et al., 2008). This can lead to oxidative stress formation, which may inhibit cells proliferation and differentiation (Jung, 2014). The formation of oxidative stress is a consequence of an imbalance between oxidative processes, conditioned by the level of ROS and antioxidant defences of treated cells (Beytut et al., 2018). In this study, both osteoblasts and fibroblasts cultured on hydroxyapatites show an increase in intracellular ROS generation, which can promote oxidative and pro-inflammatory conditions (Biswas, 2016). Enhanced ROS generation in oste- 
oblasts may reduce the rate of proliferation and expression of bone morphogenetic protein genes (BMP2, BMP7, and BMP4) (Jung, 2014) leading to an inhibition of the differentiation process, thereby disrupting alkaline phosphatase activity and synthesis of collagen type I and osteocalcin (Arai et al., 2007). This study has demonstrated just how sensitive the osteoblast proliferation process is to the presence of xenogeneic biomaterial, in particular, of porcine origin (Apatos). Hydroxyapatites of allogeneic origin (Maxgraft), as well as xenogeneic bovine origin (Cerabone) and porcine hydroxyapatite with preserved collagen (Genos), show less disturbances to the proliferation of osteoblasts. Thus far, metabolic changes in fibroblasts in the presence of hydroxyapatite have not been evaluated. To the authors' knowledge, this paper is the first to report an increase in ROS generation by fibroblasts cultivated in the presence of hydroxyapatite leading to an enhanced pro-oxidative response and as a consequence, reduced proliferation, according to the literature (Formichi et al., 2006). Previously, proliferation of human mesenchymal cells (hMSCs) was shown to be inhibited by hydroxyapatite (Weißenböck et al., 2006; Xu et al., 2012).

Regardless of the intensity of ROS production, the antioxidant capacity of cells is weakened, revealed by a decrease in GSH level of osteoblasts grown on hydroxyapatites and fibroblasts grown on xenogenic hydroxyapatites. Diminished GSH level may disrupt the biological membrane protection system, which depends on GSH (glutathione peroxidase glutathione - glutathione reductase) (Hatori et. al., 2018). Alterations in the antioxidant capacity of osteoblasts and fibroblasts cultivated on hydroxyapatites may also be the result of an increase in expression of Nrf2 transcription factor, which participates in the activation of antioxidant response genes (ARE) encoding cytoprotective proteins, including antioxidant proteins (Gęgotek and Skrzydlewska, 2015). In the case of osteoblasts, a particularly significant increase (5-fold) in the expression of Nrf2 occurred in the presence of xenogeneic biomaterial (Cerabone, Genos, and Apatos), whereas fibroblasts showed increased expression after exposure to xenogeneic Cerabone and Genos as well as allogeneic Maxgraft. Enhanced expression of Nrf2 may indicate an enhanced antioxidant response by cells to oxidative conditions. Metabolic changes in MC3T3-E1 osteoblasts with an increased Nrf2 level have also been observed. Since Nrf2 transcription factor may bind to DNA at the Runx2 site reducing its expression, this may result in decreased transcription of ALP and consequently, mineralization of the extracellular matrix (Hinoi et al., 2006). These studies suggest the osteoblast mineralization process may depend on redox signal transmission in cells, which may be disrupted by hydroxyapatites.

A consequence of redox imbalance due to the influence of hydroxyapatites is oxidative stress, manifested as increased peroxidation of membrane phospholipids seen by elevated MDA level which is one of the peroxidation products and oxidative modifications of proteins evaluated by elevated level of protein carbonyl groups. Observed changes correspond to the inhibition of osteoblasts differentiation due to the presence of hydroxyapatites. Previously, oxidation of structural proteins was shown to inhibit mineralization, and was accompanied by decreases in collagen type I synthesis and alkaline phosphatase activity (Arai et al., 2007). Our study suggests that fibroblast proteins are much more susceptible to oxidative modifications than osteoblast proteins. Moreover, in both cases, xenogeneic hydroxyapatites had a stronger influence on redox balance than allogeneic biomaterial.

Oxidative stress associated with the presence of bone-derived hydroxyapatites may also be involved in the activation of the NFkB transcription factor, responsible for the synthesis of proinflammatory cytokines (Shih et al., 2015) as well as differentiation of osteoblasts (Zhong et al., 2009). The bone resorption process is mediated by NFKB via the RANK/RANKL/OPG pathway (Glass et al., 2005), which is associated with bone regeneration, however, too high expression may lead to bone loss and is typical of many bone diseases (Yao and Camacho 2014).

Summarizing the effects of hydroxyapatites on the redox balance and metabolism of osteoblasts and fibroblasts, it can be concluded that xenogeneic biomaterials have the strongest effect. This is consistent with the literature, which indicates that the effects of bone-derived hydroxyapatites depend on their origin (Kolk et al., 2012). Enrichment of hydroxyapatite with collagen (Genos) may promote metabolic disorders associated with the previously recognized immunogenic nature of such biomaterial (Lynn et al., 2004).

\section{Effect of Emdogain on osteoblasts and fibroblasts cultured in the presence of hydroxyapatite-based biomaterials}

In contrast, biomaterial like Emdogain supports bone regeneration and post-operative wound healing thanks to the enamel matrix proteins contained in its composition. The enamel matrix proteins contain mainly amelogenin (90\%), enamelins, ameloblastin, tuftelin, and growth factors (BMPs and TGF- $\beta$ ). Emdogain was previously used to reduce the effects of hydroxyapatites on metabolic functions of osteoblasts (Wada et al., 2012). Redox balance in osteoblasts is restored by enamel matrix proteins probably due their osteoinductive properties, which promote the mineralization process, resulting in increased biosynthesis of DNA, collagen type I, and osteocalcin, as well as enhanced alkaline phosphatase activity (Fukuda 2013; Miron et. al. 2017; Wada et al., 2012). Moreover this study results indicate that Emdogain reduces the level of ROS and increases concentrations of the main non-enzymatic cell antioxidant, GSH, in both cell types, including osteoblasts and fibroblasts cultured on hydroxyapatites. The enamel matrix derivative is particularly effective in fibroblast cultures, lowering the level of ROS below level of control cells, whereas the strong influence of Emdogain is visible in osteoblasts cultured in the presence of all biomaterials. Significant decreases in ROS level can reduce oxidative conditions and may possibly prevent modification of cell components, such as peptides (for example, GSH), proteins (decreased level of carbonyl groups), and phospholipids (decreased the level of lipid peroxidation products - MDA). Reducing oxidative conditions by Emdogain also favours lower expression of Nrf2. Suppression of Nrf2 has been associated with inhibition of osteoblast proliferation and differentiation by decreasing level of key regulatory proteins, such as Runx2, osteocalcin, and Osterix (Park et al., 2014). Animal studies have shown that Nrf2 reduction in bone tissue leads to lower bone mass, manifested as lower bone mineral density (Sun et al., 2015). This may be caused by the presence of growth factors such as TGF- $\beta$ and BMPs (Bosshardt, 2008), which play an important role in regulating osteogenic processes. These factors may influence, among others things, the signalling pathways associated with activation of Nrf2 and NFKB (Jimi et al., 2014), and transcription factors responsible for osteoblasts differentiation, such as Runx2 and Osterix, as well as stimulating migration and proliferation of fibroblasts to promote wound healing in vivo (Rincon et al., 2003). Additionally, suppression of ROS level and decrease in NFkB expression as a result of Emdogain exposure may modulate proinflammatory responses. In both fibroblasts and osteoblasts it was shown 
that contact with hydroxyapatite leads to visible increase of $\mathrm{NF} \kappa \mathrm{B}$ expression. The influence of transcription factor NFkB on osteoblasts is related to its participation in the inflammatory process by activating proteins associated with pro-inflammatory factors and secondary cytokines (Novack, 2011). Reduced NFkB level observed after using Emdogain may also be seen during the differentiation process of these cells since activation of NFkB directly inhibits BMP-2-induced differentiation of osteoblasts (Jimi et al., 2014). This may be attributed to reduced expression of genes involved in early phases of the inflammation process (proinflammatory factors such as IL-6, IL-13, and interferon $\gamma$ ) during wound healing and increased expression of genes responsible for growth and repair of cells, such as those encoding for the growth factors and growth factor receptors that support the regeneration process (Jiang et al., 2006; Parkar and Tonetti, 2004). Emdogain has proven to be most effective for osteoblasts and fibroblasts grown on bovine (Cerabone) and porcine (Genos) hydroxyapatite.

\section{Conclusions}

In summary, hydroxyapatites, particularly those of xenogeneic origin, do not have cytotoxic effects on osteoblasts, however, they may contribute to enhanced oxidative and pro-inflammatory conditions. This results in oxidative modifications of the lipids and proteins, leading to disturbance of the proliferation and differentiation of osteoblasts and fibroblasts. In contrast, enamel matrix derivative components of Emdogain partially demonstrate antioxidant activity, thereby prevent the production of ROS and increase the antioxidant capacity of cells. Therefore, adding Emdogain to the medium of cells in culture reduces oxidative stress and inhibits inflammation caused by hydroxyapatite, particularly those of xenogeneic origin.

\section{Conflict of interest}

The authors have no conflict of interests to declare.

\section{References}

Anderson JM, Rodriguez A, Chang DT (2008). Foreign body reaction to biomaterials. Semin Immunol 20(2): 86-100. DOI: 10.1016/j. smim.2007.11.004.

Arai M, Shibata Y, Pugdee K, Abiko Y, Ogata Y (2007). Effects of reactive oxygen species (ROS) on antioxidant system and osteoblastic differentiation in MC3T3-E1 cells. IUBMB Life 59(1): 27-33. DOI: 10.1080/15216540601156188.

Augustyniak E, Adam A, Wojdyla K, Rogowska-Wrzesinska A, Willetts R, Korkmaz A, et al. (2015). Validation of protein carbonyl measurement: A multi-centre study. Redox. Biol 4: 149-157. DOI: 10.1016/j.redox.2014.12.014.

Baldini N, De Sanctis M, Ferrari M (2011). Deproteinized bovine bone in periodontal and implant surgery. Dent Mater 27(1): 61-70. DOI: 10.1016/j.dental.2010.10.017.

Behnia H, Khojasteh A, Kiani MT, Khoshzaban A, Mashhadi Abbas F, Bashtar M, Dashti SG (2013). Bone regeneration with a combination of nanocrystalline hydroxyapatite silica gel, plateletrich growth factor, and mesenchymal stem cells: a histologic study in rabbit calvaria. Oral Surg Oral Med Oral Pathol Oral Radiol 115(2): 7-15. DOI: 10.1016/j.oooo.2011.09.034.

Beytut E, Yilmaz S, Aksakal M, Polat S (2018). The possible protective effects of vitamin $\mathrm{E}$ and selenium administration in oxidative stress caused by high doses of glucocorticoid administration in the brain of rats. J Trace Elem Med Biol 45: 131-135. DOI: 10.1016/j.jtemb.2017.10.005.
Biswas SK (2016). Does the interdependence between oxidative stress and inflammation explain the antioxidant paradox? Oxid Med Cell Longev 2016(12): 1-9. DOI: 10.1155/2016/5698931.

Bosshardt DD (2008). Biological mediators and periodontal regeneration: a review of enamel matrix proteins at the cellular and molecular levels. J Clin Periodontol 35(85 Suppl): 87-105. DOI: 10.1111/j.1600-051X.2008.01264.x.

Colnot C, Romero DM, Huang S, Helms JA (2005). Mechanisms of action of demineralized bone matrix in the repair of cortical bone defects. Clin Orthop Relat Res 435: 69-78.

Czekanska EM, Stoddart MJ, Richards RG, Hayes JS (2012). In search of an osteoblast cell model for in vitro research. Eur. Cell. Mater. 9(24) 1-17.

Eissa S, Seada LS (1998). Quantitation of bcl-2 protein in bladder cancer tissue by enzyme immunoassay: comparison with Western blot and immunohistochemistry. Clin Chem 44(7): 1423-1429.

Formichi P, Radi E, Battisti C, Tarquini E, Leonini A, Di Stefano A, Federico A (2006). Human fibroblasts undergo oxidative stressinduced apoptosis without internucleosomal DNA fragmentation. J Cell Physiol 208(2): 289-297. DOI: 10.1002/jcp.20662.

Fotakis G, Timbrell JA (2006). In vitro cytotoxicity assays: comparison of LDH, neutral red, MTT and protein assay in hepatoma cell lines following exposure to cadmium chloride. Toxicol Lett 160(2): 171-177. DOI: 10.1016/j.toxlet.2005.07.001.

Fukuda T, Sanui T, Toyoda K, Tanaka U, Taketomi T, Uchiumi T, Nishimura F (2013). Identification of novel amelogenin-binding proteins by proteomics analysis. PLoS One 8(10): e78129. DOI: 10.1371/journal.pone.0078129.

Gęgotek A, Rybałtowska-Kawałko P, Skrzydlewska E (2017). Rutin as a mediator of lipid metabolism and cellular signaling pathways interactions in fibroblasts altered by UVA and UVB radiation. Oxid Med Cell Longev 2017: 4721352. DOI: 10.1155/2017/4721352.

Gęgotek A, Skrzydlewska E (2015). The role of transcription factor Nrf2 in skin cells metabolism. Arch Dermatol Res 307(5): 385-396. DOI: 10.1007/s00403-015-1554-2.

Glass DA, Bialek P, Ahn JD, Starbuck M, Patel MS, Clevers H, et al. (2005). Canonical Wnt signaling in differentiated osteoblasts controls osteoclast differentiation. Dev Cell 8(5): 751-764. DOI: 10.1016/j.devcel.2005.02.017.

Hatori Y, Inouye S, Akagi R, Seyama T (2018). Local redox environment beneath biological membranes probed by palmitoylated-roGFP. Redox Biol 14: 679-685. DOI: 10.1016/j. redox.2017.11.015.

Hinoi E, Fujimori S, Wang L, Hojo H, Uno K, Yoneda Y (2006). Nrf2 negatively regulates osteoblast differentiation via interfering with Runx2-dependent transcriptional activation. J Biol Chem 281(26): 18015-18024. DOI: 10.1074/jbc.M600603200.

Huggins RJ, Mendelson BC (2017). Biologic behavior of hydroxyapatite used in facial augmentation. Aesthetic Plast Surg 41(1): 179-184. DOI: 10.1007/s00266-016-0707-9.

Inayat-Hussain SH, Rajab NF, Roslie H, Hussin AA, Ali AM, Annuar BO (2004). Cell death induced by hydroxyapatite on L929 fibroblast cells. Med J Malaysia 59 Suppl B: 176-177.

Jiang J, Goodarzi G, He J, Li H, Safavi KE, Spångberg LS, Zhu Q (2006). Emdogain-gel stimulates proliferation of odontoblasts and osteoblasts. Oral Surg Oral Med Oral Pathol Oral Radiol 102(5): 698-702. DOI: 10.1016/j.tripleo.2006.02.011.

Jimi E, Hirata S, Shin M, Yamazaki M, Fukushima H (2014). Molecular mechanisms of BMP-induced bone formation: Cross-talk between BMP and NF-kB signaling pathways in osteoblastogenesis. Jpn Dent Sci Rev 46(1): 33-42. DOI: 10.1016/j.jdsr.2009.10.003.

Jung WW (2014). Protective effect of apigenin against oxidative stress-induced damage in osteoblastic cells. Int J Mol Med 33(5): 1327-1334. DOI: 10.3892/ijmm.2014.1666.

Kolk A, Handschel J, Drescher W, Rothamel D, Kloss F, Blessmann M, et al. (2012). Current trends and future perspectives of bone substitute materials - from space holders to innovative biomaterials. J Craniomaxillofac Surg 40(8): 706-718. DOI: 10.1016/j.jcms.2012.01.002.

Kornicka K, Nawrocka D, Lis-Bartos A, Marędziak M, Marycz K (2017). Polyurethane-polylactide-based material doped with resveratrol decreases senescence and oxidative stress of adipose- 
derived mesenchymal stromal stem cell (ASCs). RSC Advances 39: 24070-24084. DOI: 10.1039/C7RA02334K.

Kübler A, Neugebauer J, Oh JH, Scheer M, Zöller JE (2004). Growth and proliferation of human osteoblasts on different bone graft substitutes: an in vitro study. Implant Dent 13(2): 171-189. DOI: 10.1097/01.ID.0000127522.14067.11.

Kuzkaya N, Weissmann N, Harrison DG, Dikalov S (2003). Interactions of peroxynitrite, tetrahydrobiopterin, ascorbic acid, and thiols: implications for uncoupling endothelial nitricoxide synthase. J Biol Chem 278(25): 22546-22554. DOI: 10.1074/jbc. M302227200.

Lynn AK, Yannas IV, Bonfield W (2004). Antigenicity and immunogenicity of collagen. J Biomed Mater Res B Appl Biomater 71(2): 343-354. DOI: 10.1002/jbm.b.30096.

Maeso N, Garcia-Martinez D, Ruperez FJ, Cifuentes A, Barbas C (2005). Capillary electrophoresis of glutathione to monitor oxidative stress and response to antioxidant treatments in an animal model. J Chromatogr B Analyt Technol Biomed Life Sci 822(1-2): 61-69. DOI: 10.1016/j.jchromb.2005.05.015.

Marycz K, Pazik R, Zawisza K, Wiglusz K, Maredziak M, Sobierajska P, Wiglusz RJ (2016). Multifunctional nanocrystalline calcium phosphates loaded with Tetracycline antibiotic combined with human adipose derived mesenchymal stromal stem cells (hASCs). Mater Sci Eng C Mater Biol Appl 69: 17-26. DOI: 10.1016/j.msec.2016.06.051.

Marycz K, Sobierajska P, Smieszek A, Maredziak M, Wiglusz K, Wiglusz RJ (2017). Li+ activated nanohydroxyapatite doped with Eu3+ ions enhances proliferative activity and viability of human stem progenitor cells of adipose tissue and olfactory ensheathing cells. Further perspective of $\mathrm{nHAP}: \mathrm{Li}+, \mathrm{Eu} 3+$ application in theranostics. Mater Sci Eng C Mater Biol Appl 78: 151-162. DOI: 10.1016/j.msec.2017.04.041.

Miron RJ, Fujioka-Kobayashi M, Zhang Y, Caballé-Serrano J, Shirakata Y, Bosshardt DD, et al. (2017). Osteogain improves osteoblast adhesion, proliferation and differentiation on a bovinederived natural bone mineral. Clin Oral Implants Res 28(3): 327-333. DOI: 10.1111/clr.12802.

Morais JM, Papadimitrakopoulos F, Burgess DJ (2010). Biomaterials/ tissue interactions: possible solutions to overcome foreign body response. AAPS J 12(2): 188-196. DOI: 10.1208/s12248-0109175-3.

Mrakovcic L, Wildburger R, Jaganjac M, Cindric M, Cipak A, Borovic-Sunjic S, et al. (2010). Lipid peroxidation product 4-hydroxynonenal as factor of oxidative homeostasis supporting bone regeneration with bioactive glasses. Acta Biochim Pol 57(2): 173-178.

Novack DV (2011). Role of NF-kB in the skeleton. Cell Res 21(1): 169-182. DOI: 10.1038/cr.2010.159.

Ozeki K, Aoki H, Fukui Y (2007). The effect of adsorbed vitamin D and K to hydroxyapatite on ALP activity of MC3T3-E1 cell. J Mater Sci Mater Med 19(4) 1753-1757. DOI: 10.1007/s10856-0073288-y.

Park CK, Lee Y, Kim KH, Lee ZH, Joo M, Kim H-H (2014). Nrf2 is a novel regulator of bone acquisition. Bone 63: 36-46. DOI: 10.1016/j.bone.2014.01.025.

Parkar MH, Tonetti M (2004). Gene expression profiles of periodontal ligament cells treated with Enamel Matrix Proteins in vitro: analysis using cDNA arrays. J Periodontol 75(11): 15391546. DOI: 10.1902/jop.2004.75.11.1539.

Patti A, Gennari L, Merlotti D, Dotta F, Nuti R (2013). Endocrine actions of osteocalcin. Int J Endocrinol 2013(3): 846480. DOI: 10.1155/2013/846480.

Peterkofsky B, Chojkier M, Bateman J (1982). Determination of collagen synthesis in tissue and cell culture system. In: Furthmay M (Ed.). Immunochemistry of the Extracellular Matrix. Florida: CRC Press Boca Raton, pp. 19-47.

Rincon JC, Haase HR, Bartold PM (2003). Effect of Emdogain on human periodontal fibroblasts in an in vitro wound-healing model. J Periodontal Res 38(3): 290-299. DOI: 10.1034/j.16000765.2003.00610.x.

Sculean A, Alessandri R, Miron RJ, Salvi G, Bosshard DD (2011). Enamel matrix proteins and periodontal wound healing and regeneration. Clin Adv Periodontics 1(2): 101-117. DOI: 10.1902/ cap.2011.110047.

Shih R-H, Wang Ch-Y, Yang C-M (2015). NF-kappaB signaling pathways in neurological inflammation: A Mini Review. Front Mol Neurosci 8: 77. DOI: $10.3389 /$ fnmol.2015.00077.

Sun Y-X, Xu A-H, Yang Y, Li J (2015). Role of Nrf2 in bone metabolism J Biomed Sci 22: 101. DOI: 10.1186/s12929-0150212-5.

Tagaya M, Ikoma T, Takemura T, Migita S, Okuda M, Yoshioka $\mathrm{Tb}$, et al. (2011). Initial adhesion behavior of fibroblasts onto hydroxyapatite nanocrystals. Bioceram Dev Appl ID: D110165. DOI: $10.4303 / \mathrm{bda} / \mathrm{D} 110165$.

Theiszova M, Jantova S, Letasiova S, Palou M, Cipak L (2008). Cytotoxicity of hydroxyapatite, fluorapatite and fluorhydroxyapatite: a comparative in vitro study. Neoplasma 55(4): 312-316.

Tseng L-L, Ho C-M, Liang W-Z, Hsieh Y-D, Jan C-R (2013). Comparison of efficacies of different bone substitutes adhered to osteoblasts with and without extracellular matrix proteins. J Dent Sci 8(4): 399-404. DOI: 10.1016/j.jds.2012.03.026.

Wada Y, Mizuno M, Nodasaka Y, Tamura M (2012). The effect of enamel matrix derivative on spreading, proliferation, and differentiation of osteoblasts cultured on zirconia. Int J Oral Maxillofac Implants 27(4): 849-858.

Weißenböck M, Stein E, Undt G, Ewers R, Lauer G, Turhani D (2006). Particle size of hydroxyapatite granules calcified from red algae affects the osteogenic potential of human mesenchymal stem cells in vitro. Cells Tissues Organs 182(2): 79-88. DOI: 10.1159/000093062.

Xu Z, Liu C, Weib J, Suna J (2012). Effects of four types of hydroxyapatite nanoparticles with different nanocrystal morphologies and sizes on apoptosis in rat osteoblasts. J Appl Toxicol 32(6): 429-435. DOI: 10.1002/jat.1745.

Yao AL, Camacho PM (2014). Osteomesopyknosis: a case report and review of sclerosing bone disorders. Endocr Pract 20(6): 106-111. DOI: 10.4158/EP13352.CR.

Zhong Z-M, Bai L, Chen J-T (2009). Advanced oxidation protein products inhibit proliferation and differentiation of rat osteoblastlike cells via NF-kappaB pathway. Cell Physiol Biochem 24: 105-114. DOI: 10.1159/000227818. 